\title{
María en la tradición protestante. La inquietud, una manera de encontrarse con la sabiduría ignorada de María*
}

\author{
Blanca Camacho Sandoval ${ }^{* *}$
}

\section{Resumen}

en este artículo la autora se propone descubrir la sabiduría ignorada de María dentro de la tradición protestante a partir del diálogo y comunión con experiencias mariológicas populares de la tradición católica.

Palabras clave: María, experiencia de Dios, protestantismo, catolicismo, mujeres.

* Conferencia en el panel interreligioso del III Congreso Internacional de Teología Mariana de la Facultad de Teología de la Universidad Santo Tomás (Chiquinquirá, Boyacá), 21 de septiembre de 2012.

** Magíster en Psicología Clínica de Familia por la Universidad Santo Tomás (Colombia). Teóloga del Seminario Presbiteriano de Colombia CUR. Psicóloga de la Universidad Católica de Colombia. Docente de la Fundación Universitaria Claretiana. Correo electrónico: blanquisc02@ yahoo.com 


\section{Introducción}

Al hablar de María en la tradición protestante, me surgieron varias inquietudes que parten de mi propia experiencia, las cuales orientarán este compartir. Algunas de las primeras inquietudes que surgieron fueron: ¿quién es María para mí? ¿Cómo ha influido la tradición protestante en mi relación con María? ¿Cuál es el lugar de María en esta tradición? ¿Desde la tradición protestante, qué lenguajes se usan para hablar de María? Las inquietudes, lejos de ser obstáculos, me permitieron ir al encuentro de experiencias donde, junto con otras mujeres, nos hemos dejado contagiar de tal inquietud para descubrir la sabiduría ignorada de María en mi tradición. Así, comparto el camino que hemos hecho como mujeres al encuentro con la sabiduría ignorada de María.

Gran parte de las respuestas a mis inquietudes, así como la manera como estas se han ido resolviendo, se han ido tejiendo a través de compartir muchas preguntas y sospechas en relación con la tradición católica, revisando la mariología popular y desentramando todos sus maquillajes. Como dije, la inquietud es un lugar de partida, un lugar mediante el cual me conecto con María, un lugar desde donde ella construyó sus opciones y su encuentro con Dios. es por esto que para mí la inquietud es una "hermana opción" en este caminar (Russel, 2004, p. 338).

\section{Mirando las raíces}

Una retrospectiva histórica de los reformadores da evidencia de que aceptaron los dogmas mariológicos de los concilios ecuménicos: es decir, la proclamación de María como Theotókos (madre de Dios) aprobada en el Concilio de Éfeso, en el año 341, y el dogma de la virginidad de María aprobado en Constantinopla en 553. Los demás dogmas mariológicos: inmaculada concepción (immaculata conceptio), de 1854, y la asunción (assumptio), de 1950, no fueron reconocidos por las iglesias protestantes, porque no fueron promulgados en los concilios ecuménicos y carecen de fundamentación bíblica.

A causa del interés de los reformadores por mantener sus enseñanzas bajo la fundamentación bíblica, surgieron cuestionamientos sobre el culto a 
los santos y las exageraciones a la idolatría. en lo que respecta a María, se censuraba prestarle mucha devoción cristiana, que podía llegar a ser idolatría y ocultar la centralidad de Cristo como Salvador. en este sentido, los cuatro principios protestantes: solamente por la gracia (sola gratia), la fe (sola fide), por la escritura (sola Scriptura) y solo un Cristo (solus Christus), pretendían recuperar la fe y la gracia, como caminos para la salvación, denunciando cualquier otro enlace como penitencias, promesas a los santos o compra de indulgencias, propios de la época, que eran considerados desvíos del camino a Dios. De esta manera, María permanece siendo modelo de fe, pero a diferencia de Cristo, no es redentora ni mediadora entre Dios y la humanidad.

en un estudio realizado por Pelikan, sobre un texto de 1612 recopilado por walter Trappolet y titulado Los reformadores alaban a María, se reúnen una serie de textos de Lutero, Calvino, zwinglio y Bullinge, que revelan la ortodoxia del lenguaje y de las enseñanzas sobre María, además del fervor y la dedicación. Por ejemplo, se encontró que zwinglio declaraba que Ma- ría era la "Madre de Dios" y "la más excelsa de las criaturas después de su Hijo". Baltasar Hubmaier defendía la virginidad eterna de María y Lutero, por su parte, lo hacía tanto en sus escritos como en sus sermones y afirma- ciones: "así como ella era virgen antes de dar a luz, después del parto ella así permaneció". Las iglesias protestantes conservaron muchas festividades ligadas a María. Las que no tenían fundamento bíblico fueron eliminadas y otras fueron consideradas como festivos parciales (su concepción, su nacimiento y asunción) (Deifield, 2003).

De Lutero es de quien más se encuentran sermones sobre María, quien predicaba precisamente en los días festivos. Su escrito más conocido es su comentario al Magnificat (1520-1521). en este escrito, Lutero hace un análisis del texto bíblico de Lucas 1,46-55 y lo presenta como una fundamentación para una ética política. María es presentada, repetidamente, como un ejemplo a ser seguido. Partiendo de la experiencia de María, que se enaltece y se alegra en el Señor, por las grandes maravillas que en ella se operaron, Lutero propone que María sirva de ejemplo para una actitud ética cristiana, un modelo especial para gobernantes. Cuando Lutero fue excomulgado en 1521, sus palabras fueron: "Pueda Cristo interceder por nosotros, por amor de su querida Madre, María! Amén", parte final de su Comentario sobre el Magnificat (como se cita en Deifield, 2003). 
Lutero afirmaba que María es un ejemplo de humildad, ya que, a pesar de saberse madre de Dios, mantenía su humildad y comprendía que la acción de Dios de exaltar al humilde y abatir al grande ocurre cuando, a pesar de la humildad, pobreza e inferioridad, ella experimenta a Dios en su vida. La pobreza y la miseria no le impiden vivir su experiencia de Dios, experiencia que ella no se queda para sí, sino que comparte a través del cántico. el reformador pone especial énfasis en la palabra humillitas. Humillarse significaba ser nada, actitud que contrapone a María como la Reina del Cielo, figura con la que se identificaba en la Edad Media, por eso María es la más humilde de los seres humanos.

Por eso, según Lutero, María es ejemplo de desprendimiento; ella no busca su propio beneficio sino el de los otros; reconoce siempre la gracia y bondad de Dios en su elección. Dios es quien la escoge siendo joven, pobre y despreciada para ser madre de su Hijo, de lo cual ella no se vanagloria, sino que se despoja de sí misma y se remite a la bondad de Dios. ella se constituye como un ejemplo a seguir tanto en su humildad como en el reconocimiento que hace de la bondad de Dios. María es la primera predicadora de la encarnación de Cristo, la primera en anunciar el evangelio.

el ejemplo de María según Lutero debe ser seguido por todos los cristianos, y no solo por las mujeres, aunque en una de sus predicaciones (1532, fiesta de la visitación) invita particularmente a las mujeres a aprender de María sus virtudes, dando relevancia fundamentalmente a tres: la vida de fe, la humildad, necesaria para luchar contra la vanidad femenina, y la castidad. Asimismo, hace un llamado a que las mujeres aprovechen el tiempo estando en la iglesia orando y escuchando la palabra de Dios, en lugar de ocuparse de bailes y compras. Lutero critica a las jóvenes que se comportan con vulgaridad, que hablan en alta voz y exageran, que no son recatadas. La modestia y la humildad de María deberían servirles de modelo.

\section{El cambio en la historia}

La visión anterior fue experimentando importantes transformaciones, al punto que la tradición protestante negó la importancia de María y, en gran medida, la olvidó. Una mirada más cercana, una mirada latinoamericana, 
nos muestra que este hecho fue favorecido porque el protestantismo latinoamericano negó la veneración a los santos y, en particular, a María, considerada la mayor de todos los santos. El interés por mantener un perfil anticatólico en el protestantismo produjo intolerancia hacia la imagen de María, que fue más radicalizada en algunos lugares que en otros, considerando su culto como idolatría y llegando a extremos de identificarlo como pagano debido a la veneración de imágenes, hecho que tiene sus raíces históricas (Deifield, 2003).

Siguiendo la línea de las inquietudes que orientaron este escrito y en orden a la segunda pregunta planteada inicialmente (¿Cómo ha influido la tradición protestante en mi relación con María?, y me refiero no solamente a mí sino a otras mujeres que junto conmigo han recibido la misma herencia), y en conexión con este análisis que llevo, me pregunto: ¿pudo este ejercicio separatista y de "limpieza" librar al protestantismo de cualquier discurso relacionado con María? ¿qué aspectos de la visión católica de María mantuvieron los protestantes? La respuesta es reveladora: si bien es cierto que el protestantismo redujo cualquier posibilidad de hablar de María, no dejó de reproducir el modelo moral derivado de ella y lo prescribió a las mujeres protestantes, es decir, la crítica no llegó hasta esos terrenos, que han sido fielmente fecundados por el machismo, sus valores y patrones de comportamiento.

el modelo moral de María del catolicismo se convierte en modelo para toda mujer, y por supuesto también para las mujeres protestantes. La integridad virginal, la entrega y sumisión, el amor maternal incondicional, se mantienen como ideales para cualquier mujer. Ser madre es un imperativo insustituible de realización para las mujeres, pero eso no es todo: hay también un discurso moralizante en la imagen de María: ella es una mujer pasiva, a través de la cual se exaltan como virtudes propias de la mujer la modestia, la aceptación resignada de la voluntad de Dios, la vida escondida y la idealización de la maternidad.

el tema del cuerpo también conlleva un modelo impuesto que no ha sido muy liberador, especialmente para las mujeres creyentes. Los ideales, aunque hoy han cambiado significativamente, se mantienen en un imaginario colectivo que da cuenta de los valores sobre lo positivo, negativo, magnífico, valorable en las mujeres, y en una ética que fundamentalmente educa 
en la negación de su autonomía. De ahí que la sexualidad sea otro campo más de impacto. este modelo moralizante lleva a las mujeres a sentirse y vivirse, por lo general, desde un simbolismo que responde al modelo de mujer representado por la iconografía religiosa y la literatura de gran parte de la historia de la Iglesia, aunque cabe decir que las transformaciones han sido significativas y las mujeres han hablado se su sexualidad valorándola y haciéndola valorar. No obstante, aún queda mucho por recorrer.

\section{¿Y qué papel desempeña la inquietud?}

Con todo lo anterior, la inquietud, nuestra guía en este ejercicio, nos ayuda a percatarnos de que los lenguajes que se usan para hablar de María construyen realidades vitales, en las que hay que buscar la manera como acontece Dios; son los lugares de experiencia teológica que cada persona tiene, lo reconozca o no. Expresar una visión de María significa en el fondo hablar de la imagen de mujer que se concibe, y ¿cuál sería entonces tal imagen de mujer cuando María es concebida como sumisa, tierna, abnegada, virgen? ¿Cuál es la espiritualidad que subyace a este lenguaje y expresión? y si lo miramos desde nuestro contexto, ¿qué implican para las mujeres latinoamericanas estas descripciones en una cultura popular, con un marco androcéntrico en el que persiste constantemente un vínculo entre feminidad y subordinación?

Por eso la inquietud precisamente nos lleva al encuentro con la sabiduría ignorada, suprimida o alternativa dentro y fuera. Por ejemplo, en los aportes de las mujeres y su construcción alternativa de la realidad, me refiero a las mujeres pobres, campesinas, afrodescendientes, indígenas, pobres entre los pobres. También incluyo las fuentes de otras tradiciones religiosas cuyas intuiciones nos abren horizontes, o en las narraciones y experiencias de los pobres y excluidos que nos sitúan en otra posición de la pirámide social. Hay esperanzas. Se van modelando nuevos lenguajes sobre María y, en coherencia, se van orientando nuevos modos de vivir juntos, con todos y con la tierra.

Se trata entonces de liberar a María de su ancestral cárcel del lenguaje de categorías preestablecidas y proponer un lenguaje integral, integrado e integrador. el lenguaje no es inocente y condiciona no solo un modo de 
comunicación, sino que, ante todo, es fruto de una cosmovisión, de una manera de situarse ante las cosas. esto, trasladado al lenguaje con el que se describe o ignora a María, contribuye a su efectiva discriminación. Al ser descrita desde un lenguaje patriarcal (femenino en oposición a lo masculino), María es invisibilizada y desposeída de su plenitud. y, al serlo ella, también lo somos nosotras, mujeres a quienes se nos ha impuesto seguir este particular ejemplo (autodonación, sumisión, silencio, abnegación, entrega incondicional, humildad, obediencia). Lo cierto es que, con este lenguaje, la infinita sabiduría y riqueza de María quedan opacadas por el monopolio de los lenguajes encapsulados y de los significados culturales que se les atribuye a estos lenguajes.

De esta manera perdemos de vista aspectos tan profundos y significativos como la santidad de María. María es una santa, sí, y lo es por su relación con Dios y por estar llamada a construir una relación profunda y comunitaria con Él. Esto se traduce en una propuesta inquietante a la definición tradicional, que dice María es una santa por ser virgen, por dar a luz y seguir siendo virgen, y por su condición de sierva. María fue además una mujer, estuvo presente en cada momento vital de la vida de su hijo Jesús; su presencia es testimonio de fe. ella creía, y creer es una decisión personal: lo hizo desde su ser mujer.

Por otra parte, el lenguaje no solo expresa el mundo, sino que lo crea. y cabría preguntarnos: ¿estamos contentas con esta visión de María hecha a imagen y semejanza de ese concepto de feminidad? ¿A quién favorece o aprovecha esa conceptualización? A unos pocos, lo sabemos de sobra. Por eso es imperativo conjurar esas imágenes de la mente y el corazón. ¿Cómo? ¿Dónde buscar un lenguaje distinto, alternativo e inclusivo? La respuesta es: la realidad no es solo lo dado, también es lo posible. No podemos reducir a María a estas categorías preestablecidas, podemos seguir su ejemplo: ella fue en búsqueda de su propia capacidad de inquietarse, fue madurando en su corazón el tomar conciencia de su compromiso, a través del cual se hace ella misma y se muestra tal cual es. La inquietud de María es encuentro consigo misma, con Dios y con el otro en el aumento progresivo de su autonomía como persona. es una experiencia inquietante que se circunscribe en el plano de los conflictos vitales (Vivas, 2011). 
La inquietud nos ayuda a descubrir que, efectivamente, el protestantismo, al tratar de ir en contra de la idolatría y la opresión, hizo uso de un lenguaje excluyente para describir a María, y contrariamente mantuvo rasgos de opresión e idolatría. Al hacerlo, justifica las estructuras sociales de dominio-subordinación, opuestas a la genuina e igual dignidad humana de las mujeres, al mismo tiempo que limita el misterio de Dios. Ahora bien, dado que las visiones están empapadas de idolatría masculina: ¿cómo hablar de María incluyendo la experiencia de las mujeres? ¿Cómo nombrar y simbolizar a María de modo que su experiencia quede suficientemente reflejada? ¿Cómo construir una relectura de su experiencia que ilumine y provea sabiduría para seguir buscando las diversa formas como el lenguaje empobrece a las personas (y con ello a los seres humanos, porque cuando las mujeres son empobrecidas, el hombre, la tierra, la vida en todas sus manifestaciones son empobrecidas)?

Tengo que decir que el lugar de María en la tradición protestante se ha ido desdibujando a fuerza de influencias excluyentes. Las mujeres, y también los hombres, en las iglesias protestantes, hemos aprendido a ignorar a María. Hablar de María es poco común, y si lo hacemos, nuestro espacio es la periferia, detrás de los telones. Sin embargo, no podemos renunciar a este espacio que tenemos mientras vamos transformando lo que debemos, lo que en justicia nos corresponde.

\section{Reencontrar el camino}

es necesario encontrarse con nuevas experiencias espirituales articuladas que desemboquen, sin duda alguna, en un nuevo lenguaje sobre María. experiencias que nutren las búsquedas de quienes la inquietud anima: experiencias ecuménicas, diversas, plurales. La legitimidad de los símbolos de María requieren una nueva comprensión, entonces, desde esta perspectiva experiencial de integración y liberación de las mujeres, y por supuesto de los hombres. Cuanto más variadas y ricas sean estas imágenes, habrá más posibilidades de mostrar las innumerables aristas de la sabiduría de María. enunciar estas imágenes de manera polifacética contribuye a fortalecer dinámicas, sugerir realidades complejas y abiertas. Seremos capaces también 
de acoger como gracia los cambios que van emergiendo (María llena eres de gracia, el Señor está contigo). en otras palabras, tendremos menos posibilidades de ser dogmáticos y así será posible ensayar un lenguaje emancipador, en fidelidad al misterio de Dios de bondad, que participa de esa Bondad con mayúsculas para mujeres y hombres.

Sin embargo, como los símbolos femeninos están insertos en un contexto patriarcal, no pueden ser asumidos sin que antes hayan pasado por una hermenéutica y exhaustiva crítica:

De otro modo, lo que resulta sin más es una visión de los símbolos femeninos como "complementarios" de los generados por la experiencia masculina, visión que desemboca en la consideración de los símbolos femeninos como suplementarios, subordinados y estereotipados dentro de un marco dualista" (Schüssler, 1989, p. 141).

en cambio, cuando dichas imágenes han pasado por una hermenéutica de género se hace más factible la práctica liberadora de una comunidad de discípulas y discípulos en relación de reciprocidad. Generar un lenguaje que incluya la experiencia de las mujeres, que se entrelace con la riqueza de antiguos símbolos y permita construir un discurso y símbolos más emancipadores sobre María, amplía la proclamación “¡María llena eres de gracia! el señor está contigo". Esto significa reconocer el protagonismo ignorado de María, quien es partícipe con Dios, es escogida para actuar junto con Dios en la nueva creación; ella participa en su totalidad, mente, cuerpo y espíritu, discerniendo, dialogando y tomando decisiones.

María se nos manifiesta como una mujer sorprendida por el amor de Dios por su pueblo, su fe brota de inmediato, como fruto de su deliberación personal, como un gesto ético, y al mismo tiempo como acogida gozosa de la acción de Dios en ella (Mena, 2009).

este ejercicio comienza al reinterpretar que cuando María guarda las cosas en su corazón, en Lc 1,18, no se refiere a una acción de inactividad, de conformismo ingenuo; se refiere a la construcción personal que es preguntada en lo profundo de ser donde ocurre el diálogo con la mente sabia, que anida en cada ser humano. y desde este lugar de sabiduría, a través del Magnificat, María "relee la historia de los patriarcas desde la perspectiva de 
su propia inclusión y de la reivindicación para la realización y afirmación del derecho a la dignidad de las personas excluidas" (Richter, 2003).

"A veces nuestros conocimientos están cargados de dependencia y no de autonomía" (Lagarde, 2005). Por eso es necesario abandonar la dependencia para ir al encuentro de la invitación que María nos hace de imitarla, no como una reproducción mecánica, servil y despersonalizante, sino más bien como un reproducir el orden interno en nuestra vida en una situación siempre nueva y diversa de persona a persona. Seguir el ejemplo de María quiere decir que nuestros conocimientos y saberes pueden constituirse en efectivos aliados de la autonomía de las mujeres. Constatar que los enfoques fragmentarios no se corresponden con la realidad, nuestra opción, como siempre, está en la realidad y en la palabra. "Tenemos que revisar nuestras normas de vida cotidiana en cada relación, en cada momento, en cada espacio y en cada circunstancia. y tenemos que revisar las normas que tenemos instaladas en la subjetividad como normas divinas" (Lagarde, 2005).

María nos invita a hacer una lectura desde la periferia donde las mujeres han estado obligadas a estar, pero donde Dios decide morar, donde Dios esta con-tigo y con-migo; la periferia puede ser un nuevo enfoque del significado de la fe y la lucha que simbolizan a María. Releer las escrituras y la tradición desde la periferia es el camino hacia la opción de ser mujer que María propuso; es una marcha de autoliberación, junto con otras personas; es un camino espiritual para descubrir lo que Dios quiere que seamos, y muchas veces eso significará "desencajar" y optar por la plena humanidad de todas las mujeres y los hombres. Optar por mí misma: esta opción es una oportunidad de escoger cómo ocurrirá y cómo no ocurrirá; la opción significa superar determinados y viejos roles asignados por la cultura, la familia la religión o la sociedad patriarcal, para mujeres y hombres. es la habilidad de reinventarnos a nosotras mismas como una dimensión espiritual que moldea la historia de las mujeres y hombres a medida que se transforma la imagen que la visión patriarcal nos ha impuesto, en una imagen que concuerda con nuestra propia realidad interna, imitando a María cuando guarda las cosas en su corazón, cuando desde allí las discierne.

es un don de vinculación con nosotras mismas, en el que sabemos en lo más profundo de nuestro ser que somos amadas y aceptadas por Dios, y también por nosotras mismas. este es un momento de gracia en el que nos 
decimos: "No hay otra opción más que esta". esta conciencia del don de vinculación con nosotras no permanece siempre, y lo digo particularmente por nosotras las mujeres. Soy más cercana a esta experiencia que a la de ellos. A medida que nuestros cuerpos cambian, y nuestra vida y relaciones se modifican, tenemos que volver una y otra vez a optar por nuestro cuerpo y por nosotras mismas, abrazar nuestros dones y hacer algo con ellos en nuestro viaje por la vida.

María debe ser pensada no como símbolo de mujer, sino como el símbolo de la humanidad nueva, libre de las relaciones de poder, propias de la cultura patriarcal de dominación. La humanidad nueva, cuya naturaleza y cuyas posibilidades permanecen veladas y distorsionadas en un cristianismo todavía fundamentado sobre el dualismo sexista, es la humanidad renovada, divinizada. Para activar el papel social de la mariología será preciso volver a la María histórica, muchacha de pueblo, pobre campesina, mujer de fe, llena de esperanza, y a la figura lucana de María, animada por la espiritualidad de los pobres de yahvé, profetisa de la liberación en su Magnificat (Salazar, 2009).

María nos invita hoy, aquí, ahora, mujeres, hombres, católicos y protestantes, a convertirnos. La conversión que ella nos propone hemos de entenderla como una manera de afirmar la fortaleza, la dotación y la responsabilidad propias, la llamada a la existencia de muchos "yo suprimidos", y la presencia de "el espíritu de Dios como símbolo femenino Shekinah, que significa 'morada' o 'el que mora'". Es una invitación a conocer nuestra fuerza, nuestros recursos y nuestras responsabilidades, a conectarse con el poder que está en nosotras. ¿Qué significa llamar a la existencia a los yo suprimidos? ¿Cuáles son esos "yo suprimidos"? ¿en la diversidad de nuestra experiencia, qué creemos, sentimos y vivimos las mujeres y los hombres como conexión con el poder interior?

La preguntas son ejercicios de simple curiosidad, de inquietud, de querer investigar, de ir en pos de nuestra propia sabiduría, de detenerse a observarnos, mirando con honestidad lo que somos. Convertirnos a nosotras mismas es regalarnos el tiempo para conocernos, para encontrar el propio ritmo interno y seguirlo. Convertirse es una acción de compromiso permanente para ir al encuentro con nosotras mismas, sabiendo que la invitación 
constante es ir hacia afuera, es descentrarnos. Convertirnos es estar disponibles para nosotras mismas, en totalidad, en plenitud:

El encuentro silencioso no verbal con el misterio infinito constituye la condición que posibilita cualquier experiencia de uno mismo lo cual se conecta con mi experiencia de Dios. en y a través de la experiencia de conversión de las mujeres y hombres, sus múltiples formulaciones posibilitan nuevos lenguajes de Dios (Johnson, 1992, p. 55).

Porque Dios mora en nosotros, su presencia es testimonio de buenas nuevas y vida abundante. y porque desde este lugar sagrado es posible estar plena y enteramente presente con los demás.

María, nombrada desde estas dimensiones, es una hermana, una cercana en el seguimiento a Jesús. María es también testimonio y ejemplo como discípula y ella lo es tanto en el sentido histórico de haber acompañado a Jesús durante su ministerio, como en el sentido existencial de haber escuchado la palabra de Dios y actuado en consecuencia. Hacer memoria de María es particularmente significativo para la Iglesia, porque en ella encontramos un estilo de seguimiento de Cristo que se distingue por la coherencia y la fidelidad. Podríamos inventariar algunos criterios de legitimidad para el lenguaje simbólico en mariología: no solo coleccionar los símbolos provenientes de la tradición, sino también seleccionarlos; procurar que no degeneren en tópicos reinterpretándolos para la actualidad, usándolos con sobriedad y refiriéndolos a la verdad del dato bíblico. Así María podrá y deberá ser hoy un símbolo cristiano. y como es propio del símbolo ser el fragmento que revela el todo, en este fragmento de María se revela quién es Dios y quién es el ser humano delante de Dios.

\section{Conclusión}

Siendo María una mujer ejemplar, sería concluyente favorecer desde este ejemplo prácticas de promoción del liderazgo, que reconocieran y afirmaran la dignidad de las mujeres; ejercicios diversos de inclusión en las diferentes esferas de la vida eclesial, así como la construcción de relaciones de equidad entre mujeres y hombres. Será también un desafío hacer deconstrucciones 
permanentes, incansables de cualquier forma de mantenimiento de los mismos lenguajes encapsulados que legitiman visiones reducidas y discriminatorias hacia las mujeres y los hombres.

es cierto: la teología protestante está en deuda con el legado de María, con su sabiduría, con la construcción de nuevos lenguajes de lo sagrado, de lo divino desde lo femenino, desde todas las experiencias humanas posibles. estoy segura de que todos queremos un mundo más equitativo que represente a Dios y hable de ella y de Él de modo inclusivo, de manera que sea "natural". entonces no podemos seguir encasillando a Dios en nuestros estrechos esquemas mentales y existenciales, pues lo que hacemos es matar poco a poco su misterio, el de la realidad en general y el de la persona humana. Anhelamos vida en abundancia, aquella que se manifiesta en los estrados oficiales, en la periferia, en lo cotidiano, en lo irrelevante. Este anhelo que surge desde la periferia ha de ir transformando todos los demás espacios, incluyendo, naturalmente, las más "encumbradas" ágoras. Desde adentro hacia afuera, y desde abajo hacia el centro.

\section{Referencias}

Deifelt, w. (2003). María, ¿una santa protestante? Revista de Interpretación Bíblica Latinoamericana, (46), 98-112.

Johnson, e. (1992). La que Es. El misterio de Dios en el discurso teológico feminista. Barcelona: Herder.

Lagarde y de los Ríos, M. (2005). Para mis socias de la vida. Claves para el empoderamiento y autonomía de las mujeres; los liderazgos entrañables y las negociaciones en el amor. Cuadernos inacabados, 48.

Mena-López, M. (2009). María-mujer... comunidad-pueblo. Aportes para un discipulado de iguales desde la praxis mariana. Revista Optantes, 31, 7-15.

Navarro, M. (1987). María, la mujer. Ensayo psicológico-bíblico. Madrid: Claretianas.

Richter, I. (2003). María en los sinópticos una historia que se sigue escribiendo. Revista de Interpretación Bíblica Latinoamericana, 46, 32-46.

Russel, L. (2004). La iglesia como comunidad inclusiva. San José, Buenos Aires: UBL/ Isedet. 
Salazar-Sanzana, e. (2009). María: mujer santa y santa mujer. Revista Optantes, 31, 30-45.

Schüssler-Fiorenza, e. (1989). En memoria de ella. Una reconstrucción teológico-feminista de los orígenes del cristianismo. Bilbao: Desclée de Brouwer.

Tamez, e. (2003). Las mujeres en el movimiento de Jesús el Cristo. quito: Departamento de Publicaciones CLAI.

Vivas, M. del S. (2011). Cuerpo y virginidad en María. La seducción como posibilidad de construcción del Reino. Revista Albertus Magnus, 3(1), 71-82. 
